\title{
Indole-3-acetic-acid and ACC deaminase producing Leclercia adecarboxylata MO1 improves Solanum lycopersicum L. growth and salinity stress tolerance by endogenous secondary metabolites regulation
}

Sang-Mo Kang ${ }^{1 \dagger}$, Raheem Shahzad ${ }^{2+}$, Saqib Bilal ${ }^{3}$, Abdul Latif Khan ${ }^{4}$, Yeon-Gyeong Park ${ }^{3}$, Ko-Eun Lee ${ }^{3}$, Sajjad Asaf ${ }^{4}$, Muhammad Aaqil Khan ${ }^{3}$ and In-Jung Lee ${ }^{3^{*}}$

\begin{abstract}
Background: The utilization of plant growth-promoting microbes is an environment friendly strategy to counteract stressful condition and encourage plants tolerance. In this regards, the current study was designed to isolate ACC deaminase and indole-3-acetic acid (IAA) producing halotolerant bacteria to promote tomato (Solanum lycopersicum L.) growth and tolerance against salinity stress.

Results: The selected bacterial isolate MO1 was identified as Leclercia adecarboxylata and IAA quantification results revealed that MO1 produced significant amount of IAA $\left(9.815 \pm 0.6293 \mu \mathrm{g} \mathrm{mL}^{-1}\right)$. The MO1 showed the presence of ACC (1-Aminocyclopropane-1-Carboxylate) deaminase responsible acdS gene and tolerance against salinity stress. A plant microbe interaction experiment using tomato (Solanum lycopersicum L.) with glycine betaine (GB) as a positive control was carried out to investigate the positive role MO1 in improving plant growth and stress tolerance. The results indicated that $\mathrm{MO} 1$ inoculation and $\mathrm{GB}$ application significantly increased growth attributes under normal as well as saline condition (120 mM NaCl). The MO1 inoculation and GB treatment approach conferred good protection against salinity stress by significantly improving glucose by 17.57 and $18.76 \%$, sucrose by 34.2 and 12 . 49\%, fructose by 19.9 and $10.9 \%$, citric acid by 47.48 and $34.57 \%$, malic acid by 52.19 and $28.38 \%$, serine by 43.78 and $69.42 \%$, glycine by 14.48 and $22.76 \%$, methionine by 100 and $124.99 \%$, threonine by 70 and $63.08 \%$, and proline by 36.92 and $48.38 \%$, respectively, while under normal conditions MO1 inoculation and GB treatment also enhanced glucose by 19.83 and $13.19 \%$, sucrose by 23.43 and $15.75 \%$, fructose by 15.79 and $8.18 \%$, citric acid by 43 . 26 and $33.14 \%$, malic acid by 36.18 and $14.48 \%$, serine by 46.5 and $48.55 \%$, glycine by 19.85 and $29.77 \%$, methionine by 22.22 and 38.89\%, threonine by 21.95 and $17.07 \%$, and proline by 29.61 and $34.68 \%$ compared to levels in non-treated plants, respectively. In addition, the endogenous abscisic acid (ABA) level was noticeably lower in MO1-inoculated (30.28 and 30.04\%) and GB-treated plants (45 and 35.35\%) compared to their corresponding control plants under normal condition as well as salinity stress, respectively.
\end{abstract}

Conclusion: The current findings suggest that the IAA- and ACC-deaminase-producing abilities MO1 can improve plants tolerance to salinity stress.

Keywords: PGPR, Tomato, NaCl, Plant microbe interaction, Metabolite regulation

\footnotetext{
* Correspondence: ijlee@knu.ac.kr

${ }^{+}$Sang-Mo Kang and Raheem Shahzad contributed equally to this work.

${ }^{3}$ School of Applied Biosciences, Kyungpook National University, Daegu

41566, Republic of Korea

Full list of author information is available at the end of the article
}

(c) The Author(s). 2019 Open Access This article is distributed under the terms of the Creative Commons Attribution 4.0 International License (http://creativecommons.org/licenses/by/4.0/), which permits unrestricted use, distribution, and reproduction in any medium, provided you give appropriate credit to the original author(s) and the source, provide a link to the Creative Commons license, and indicate if changes were made. The Creative Commons Public Domain Dedication waiver (http://creativecommons.org/publicdomain/zero/1.0/) applies to the data made available in this article, unless otherwise stated. 


\section{Background}

The unpredictable climatic changes resulting from the rapidly growing population and anthropogenic activities bring various unwanted environmental stresses that negatively affect agriculture productivity [1]. Environmental changes have worsened the rigorousness of various stressors, which negatively influence the agriculture production at the present Anthropocene Era. Meanwhile, food security is needed to maintain for the growing global population by increasing crop production in sustainable and environment friendly way. Among the various environmental stresses caused by climate change, salinity stress represents a major threat to agriculture productivity $[2,3]$. Soil salinity is reported to negatively affect more than 77 million hectares, substantially reducing major crops by more than 50\% [4]. Currently, around $20 \%$ of cultivated land and $50 \%$ of irrigated land is effected by salinity stress [5]. Salinity stress has been shown to negatively affect plant growth agronomically and biochemically by reducing nearly all growth attributes, carbon acclimatization, nitrogen metabolism, and grain yield [6-8]. Salinity has three possible effects on plants, namely interfering with essential nutrient uptake, imparting toxicity because of the higher absorbance of $\mathrm{Na}^{+}$and $\mathrm{Cl}^{-}$, and lowering the water potential [9-11]. During osmotic and ionic stress triggered in plants by salt stress, the generation of active oxygen species, including superoxide $\left(\mathrm{O}_{2}-\right)$, hydroxyl radicals (. $\mathrm{OH})$, hydrogen peroxide $\left(\mathrm{H}_{2} \mathrm{O}_{2}\right)$, and singlet oxygen $\left(1 \mathrm{O}_{2}\right)$, is thought to play an important role in inhibiting plant growth; furthermore, the active oxygen species need to be scavenged for the maintenance of normal growth [12, 13].

Salt stress is a serious concern in the areas with optimum climate for tomato cultivation [14]. According to USDA, tomato is moderately sensitive to salt stress $[15,16]$. Salinity stress effect tomato growth via morphological, physiological and metabolic changes. However, many researchers reported high level of carbohydrates, amino acids, organic acids and total soluble solids in tomato plants grown in high saline conditions $[17,18]$.

A variety of methods have been used to improve crop tolerance against salinity stress, including traditional and genetic engineering methods, but one of the most promising methods is the utilization of plant growth-promoting microorganisms to promote stress tolerance and growth [19-21]. Many researchers have confirmed the effectiveness of the utilization of phytobeneficial microorganisms for stress mitigation and plant growth promotion [22-24]. Among plant growth-promoting microorganisms, plant growth-promoting rhizospheric bacteria (PGPR) are of great importance because of their direct association with plant roots [25]. PGPR are able to colonize roots, facilitate growth, and mitigate various stresses either directly by producing phytohormones (Gibberellins (GAs), Abscisic acid (ABA), Indole-3-acetic-acid (IAA)), improving nutrient uptake, producing siderophores, and solubilizing minerals or indirectly by decreasing plant pathogens $[25,26]$. Various PGPR have been found to mitigate salt stress, improve growth, and enhance tolerance in various crop plants [27-30].

ACC deaminase and IAA producing bacteria assist plant growth and can effectively protect plants against various environmental stresses, including salinity stress [31]. Rhizobacteria use tryptophan and other small molecules in root exudates and convert them into indole-3-acetic acid, which is utilized by the plant roots and resulted in the activation of plant's endogenous auxin signaling pathway, which contribute in the growth promotion and proliferation of plant cells [32]. IAA accumulation in plants induces the transcription of ACC synthase genes, which increases the ACC concentration, leading to the production of ethylene. PGPR containing ACC deaminase may break down some of the excess ACC and lower plant ethylene levels during the advent of environmental stress [33].

Within this context, this study was designed to isolate ACC deaminase and indole-3-acetic acid (IAA) producing halotolerant PGPR because the survival and adaptation of PGPR to stressful environments are important to understand and confirm the survival of bacteria in real high-saline habitats. Moreover, the current study focused on investigating the various physio-chemical responses of tomato (Solanum lycopersicum L.) with the intention to explain the regulatory networks involved in osmotic stress tolerance and enhanced salinity stress tolerance following inoculation with ACC deaminase- and IAA-producing halotolerant PGPR.

\section{Results \\ Isolation, selection and identification of Leclercia adecarboxylata M01}

The soil samples were collected from the rhizosphere of tomato (Solanum lycopersicum L.) plant at vegetative growth stage. The collected soil samples $(10 \mathrm{~g})$ were transferred to a $250 \mathrm{~mL}$ flask containing $100 \mathrm{~mL}$ Amies solution and then serially diluted to $1 \times 10^{-4}$. Then, a $0.1 \mathrm{~mL}$ suspension was spread on tryptic soy agar plates (TSA; Merck Co., Germany) and incubated at $28^{\circ} \mathrm{C}$ for $24 \mathrm{~h}$. The incubated plates were examined every $6 \mathrm{~h}$ to assess bacterial growth, and the newly appeared bacteria were re-streaked on new plates to get obtain colonies. Among total 36 isolated strains, Leclercia adecarboxylata MO1 was successfully isolated and selected on its IAA-producing capability and its ACC deaminase synthesis gene based on the Salkowski test and PCR results (Fig. 1). In addition, MO1 was grown under controlled conditions and under treatments with 120, 250, and 500 


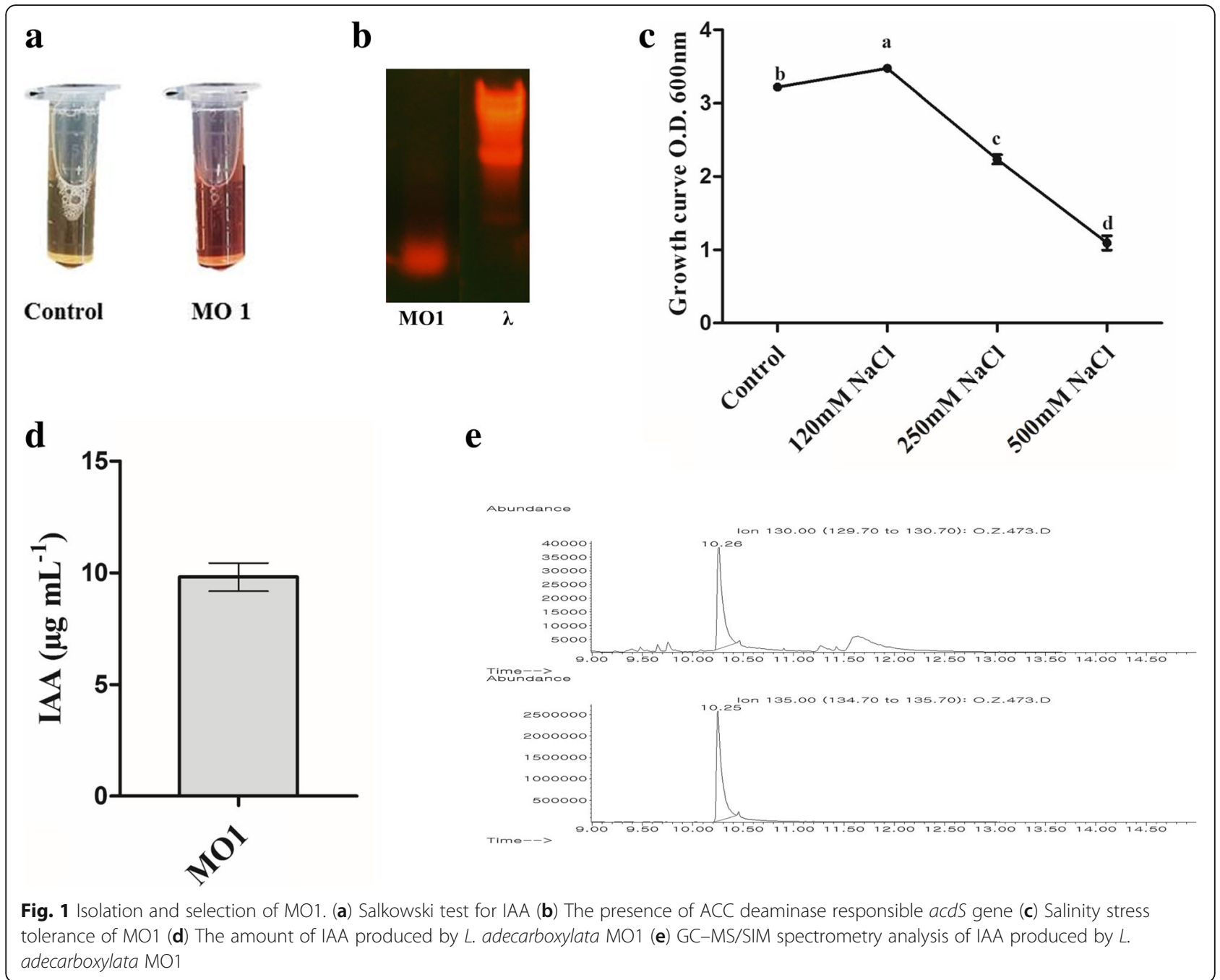

$\mathrm{mM} \mathrm{NaCl}$ to examine its growth. The results showed that MO1 had maximal growth with a cell density of $3.47 \pm 0.027$ at $\mathrm{OD}_{600}$ in medium supplemented with $120 \mathrm{mM} \mathrm{NaCl}$ compared to that under control conditions, with a cell density of $3.21 \pm 0.031$. However, the higher concentrations (250 and $500 \mathrm{mM} \mathrm{NaCl}$ ) negatively affected the growth of MO1, resulting in cell densities of $2.23 \pm 0.064$ and $1.09 \pm 0.097$ at $\mathrm{OD}_{600}$, respectively (Fig. 1).

Furthermore, MO1 was identified by $16 \mathrm{~S}$ rRNA sequencing. An NCBI (http://www.ncbi.nlm.nih.gov/) BLAST search of the 16S rRNA sequence revealed that MO1 is closely related to the genus Leclercia. To further confirm this finding, a detailed phylogenetic analysis (MEGA 6.0) was performed, closely related sequences were aligned, and a neighbor-joining tree was constructed using MEGA 6.0 (Fig. 2). The MO1 showed high sequence homology and formed a subclade with Leclercia adecarboxylata. Based on these results, MO1 was identified as $L$. adecarboxylata, and its 16S rRNA sequence was submitted to the NCBI gene bank under the accession number KP676112.

\section{IAA production by MO1}

The presence of IAA produced by MO1 in the inoculated cultural broth was initially detected with the Salkowski reagent and was further quantified by GC/MS (Fig. 1). The quantification results revealed that a significant amount of IAA $(9.815 \pm 0.6293 \mu \mathrm{g} / \mathrm{mL})$ was produced by MO1 (Fig. 1).

\section{Effects of MO1 inoculation on plant growth and stress mitigation}

The phytobeneficial and salinity stress-mitigating efficiency of MO1 were assessed by a plant microbe-interaction experiment using GB as positive and water as negative control. The results showed the positive correlation of MO1 with plant. The MO1 inoculation and $\mathrm{GB}$ treatment produced a fundamentally beneficial response under normal and stress conditions, 


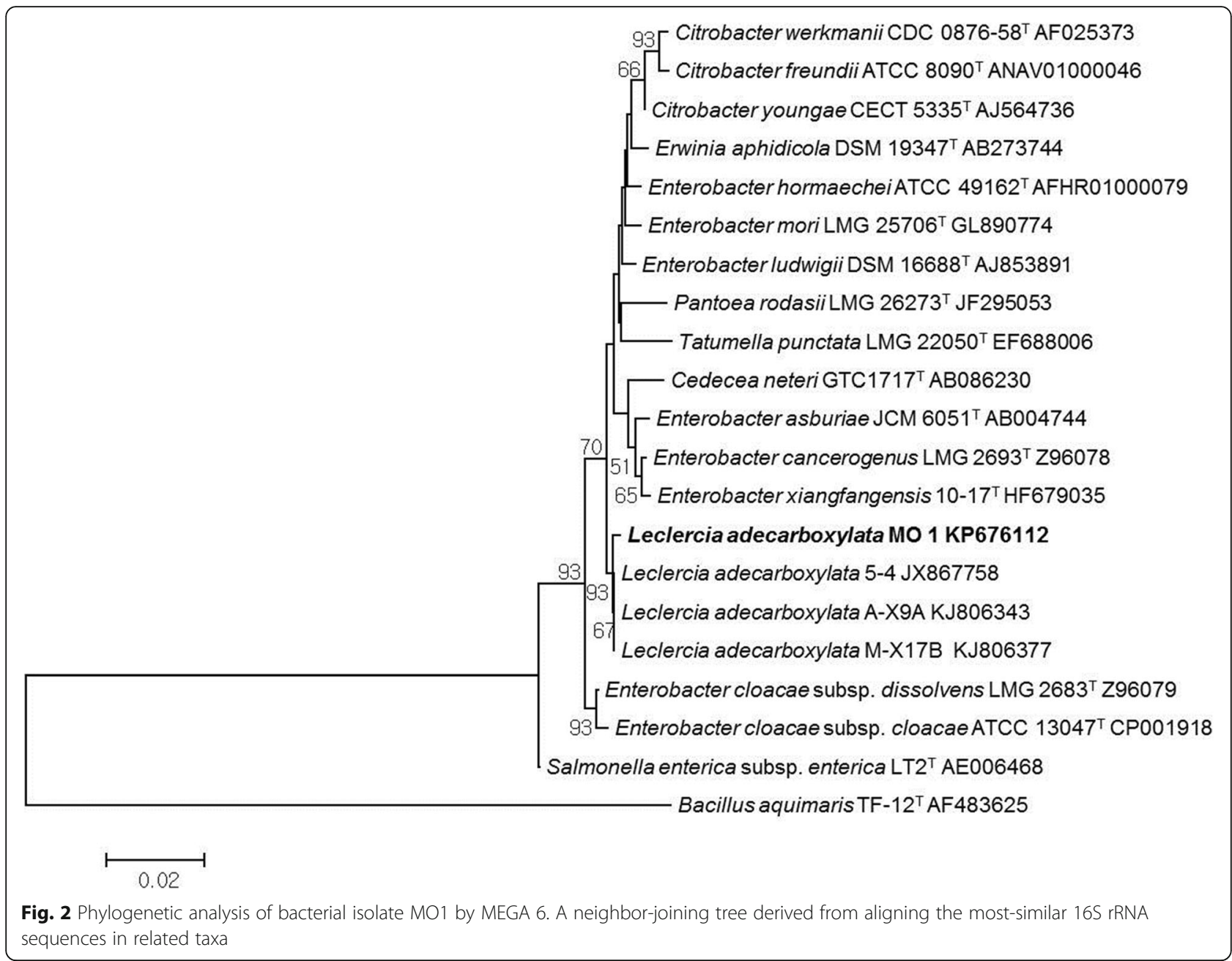

while the $\mathrm{NaCl}$ treatment resulted in a hindered and lower growth potential (Fig. 3).

MO1 inoculation and GB treatment significantly improved all growth attributes, including shoot length, with 22.09 and $18 \%$ increases; root length, with 16.3 and $12.5 \%$ increases; shoot weight, with 28.01 and $27.22 \%$ increases; root weight, with 51.15 and $47.33 \%$ increases; and stem diameter, with 15.39 and $6.44 \%$ increases, respectively (Table 1 ).

Moreover, salinity stress decreased plant growth attributes, while the MO1 inoculation and GB treatment significantly protected the plant against salinity stress (Fig. 3). Increases in shoot (39.83 and 31.43\%), root weight (82.72 and 55.56\%), and stem diameter (21.04 and $15.03 \%)$ were recorded in MO1-inoculated and GB-treated plants. Root length and shoot weight were significantly higher in MO1-inoculated plants, with 21.38 and $70.71 \%$ increases, followed by GB treatment, with 15.4 and $42.68 \%$ increases, respectively, compared to values in non-treated plants under saline conditions (Table 1).
Influence of MO1 inoculation and GB treatment on chlorophyll fluorescence

The regular exposure of plants to salinity stress suppresses and negatively regulates the chlorophyll contents. In the current study, MO1 inoculation and GB treatment significantly improved the chlorophyll fluorescence $(\mathrm{Fv} / \mathrm{Fm})$ of plants as compared to control (Fig. 4). Under normal condition, MO1 inoculation and GB treatment resulted in a higher chlorophyll fluorescence, with 15.03 and $14.39 \%$ increases, respectively, compared to that in the control (Fig. 4). Under salinity stress, a similar trend of improved chlorophyll fluorescence following MO1 inoculation and GB treatment was observed. A higher chlorophyll fluorescence was noted in MO1-inoculated and GB-treated plants, with 54.11 and $50.82 \%$ increases, respectively, compared to non-treated plants (Fig. 4).

Sugar synthesis in response to MO1 inoculation and GB treatment during salinity stress

In current study, the MO1 and GB treatments enhanced the glucose, sucrose, and fructose levels in plants grown 


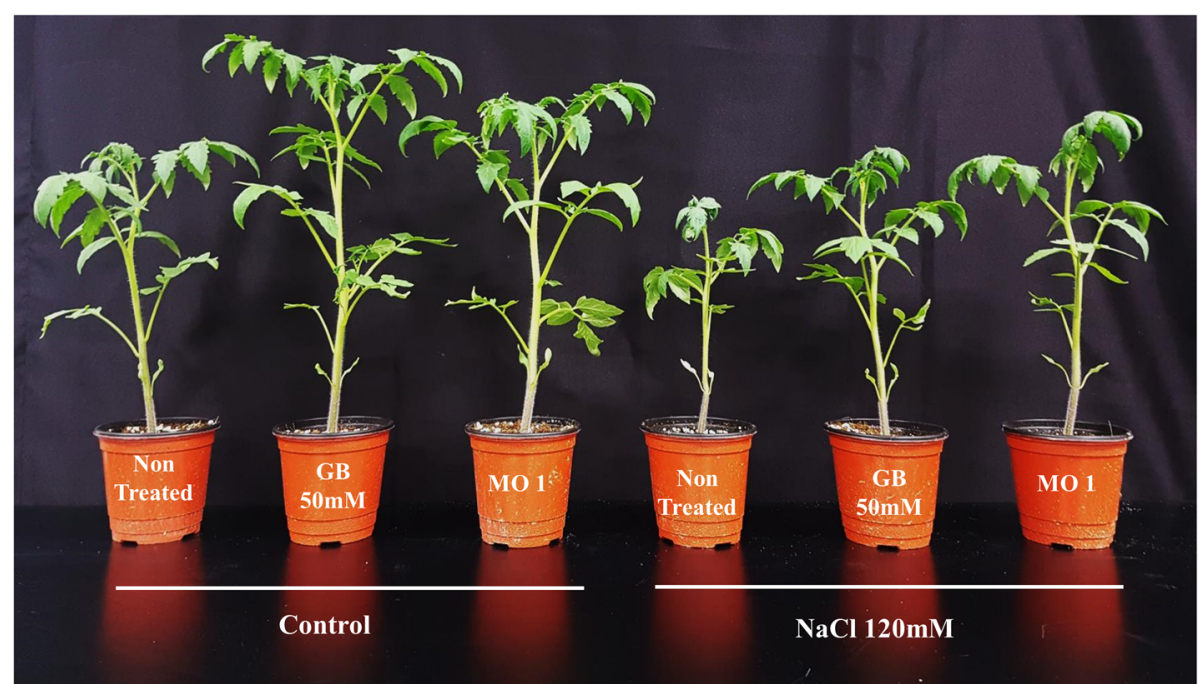

Fig. 3 Plant growth-promoting potential of MO1 inoculation and GB treatment under normal and salinity stress conditions

under normal conditions compared to non-treated plants, while a negative trend of reduced glucose, fructose, and sucrose levels was observed in plants grown under saline conditions (Fig. 5). The changes in glucose, sucrose, and fructose levels in MO1-inoculated plants represented $19.83,23.43$, and $15.79 \%$ increases, respectively, followed by increases in GB-treated plants of $13.19,15.75$, and $8.18 \%$, respectively, compared with the levels in non-treated plants under control conditions (Fig. 5).

Moreover, under saline conditions, glucose increased by 18.76 and $17.57 \%$ in GB-treated and MO1-inoculated plants, respectively, compared with the levels in non-treated plants (Fig. 5). The sucrose and fructose levels significantly increased following MO1 inoculation by 34.2 and $19.9 \%$, respectively, and following GB treatment by 12.49 and $10.9 \%$, respectively, compared to the levels in non-treated plants grown under salinity stress (Fig. 5).

\section{Organic acid regulation by MO1 inoculation and GB} treatment under salinity stress

Organic acid contents (citric acid and malic acid) were significantly modulated following MO1 inoculation and GB treatment under normal and salinity stress conditions (Fig. 6). The results revealed significantly increased amounts of citric acid (43.26 and 33.14\%) in MO1-inoculated and GB-treated plants, respectively, under control conditions (Fig. 6). Malic acid significantly increased by $36.18 \%$ following MO1 inoculation and by $14.48 \%$ following GB treatment compared to non-treated plants (Fig. 6).

A similar trend of differentially regulated citric and malic acid was found under salinity stress. The MO1 and GB treatments significantly increased the organic acid contents of plants under salinity stress (Fig. 6). The results revealed that the MO1 and GB treatments significantly increased the citric acid level, with 47.48 and $34.57 \%$ increases, respectively, compared to that in non-treated

Table 1 Effects of L. adecarboxylata MO1 inoculation and GB treatment on growth attributes of plants under normal and saline conditions

\begin{tabular}{|c|c|c|c|c|c|}
\hline & Shoot length (cm) & Root length (cm) & Shoot fresh weight (g) & Root fresh weight (g) & Stem diameters $(\mathrm{mm})$ \\
\hline \multicolumn{6}{|l|}{ No Stress } \\
\hline No treatment & $23.90 \pm 0.58 b$ & $14.72 \pm 0.37 b$ & $10.14 \pm 0.65 b$ & $1.31 \pm 0.11 b$ & $4.66 \pm 0.61 a$ \\
\hline MO1 & $29.18 \pm 0.78 a$ & $17.12 \pm 0.45 a$ & $12.98 \pm 0.29 a$ & $1.98 \pm 0.30 \mathrm{a}$ & $5.39 \pm 0.23 a$ \\
\hline 50 mM GB & $28.24 \pm 0.54 a$ & $16.56 \pm 0.40 a$ & $12.90 \pm 0.45 a$ & $1.93 \pm 0.15 a$ & $4.96 \pm 0.11 \mathrm{a}$ \\
\hline \multicolumn{6}{|l|}{ Salt Stress } \\
\hline $120 \mathrm{mM} \mathrm{NaCl}$ & $19.28 \pm 0.83 b$ & $13.38 \pm 0.50 c$ & $5.53 \pm 1.35 c$ & $0.81 \pm 0.15 b$ & $3.66 \pm 0.11 b$ \\
\hline MO1 & $26.94 \pm 0.89 a$ & $16.24 \pm 0.40 a$ & $9.44 \pm 0.46 a$ & $1.48 \pm 0.06 a$ & $4.43 \pm 0.07 a$ \\
\hline 50 mM GB & $25.34 \pm 1.16 a$ & $15.44 \pm 0.34 b$ & $7.89 \pm 0.62 b$ & $1.26 \pm 0.22 a$ & $4.21 \pm 0.14 a$ \\
\hline
\end{tabular}

Values in columns followed by different letters are significantly different at $P \leq 0.05$ among treatments based on DMRT 


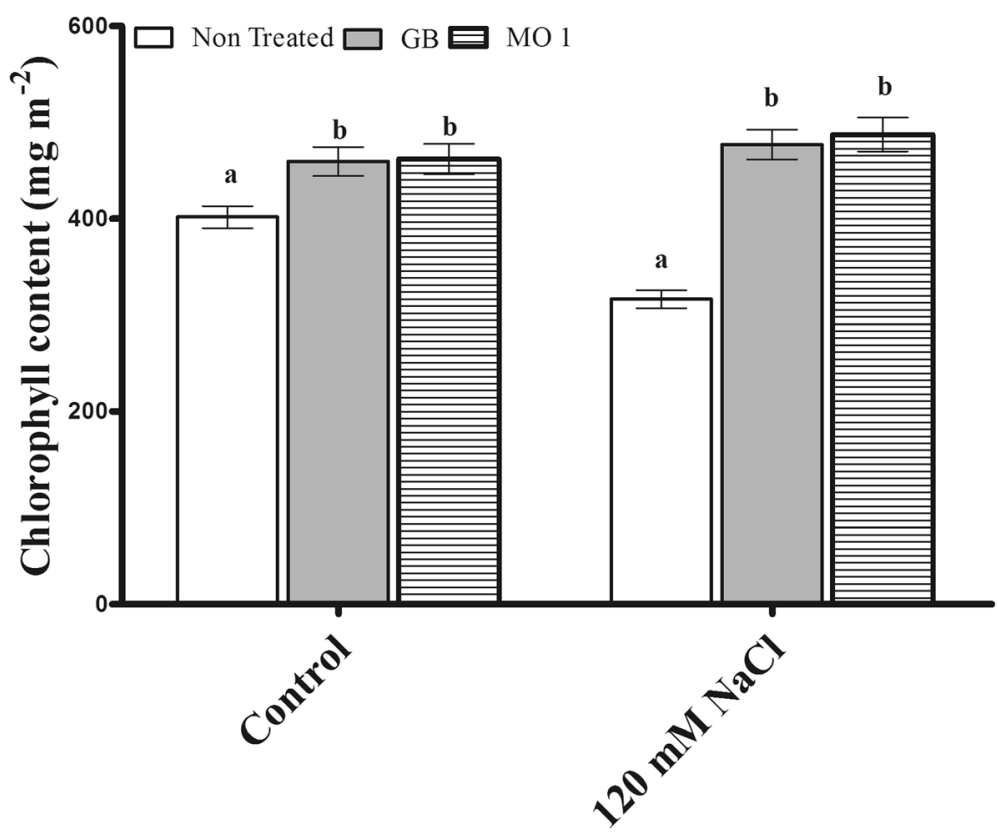

Fig. 4 Effects of L. adecarboxylata MO1 inoculation and GB treatment on the chlorophyll fluorescence (FV/Fm) of plants under normal and salinity stress conditions. Bars with different letters indicate significant differences $(P \leq 0.05)$ among treatments based on DMRT. Each value represents the mean \pm SD of six replicates from each of three independent experiments

plants (Fig. 6). Moreover, a significant increase in malic acid of $52.19 \%$ was observed in MO1-inoculated plants followed by a $28.38 \%$ increase with GB treatment compared with that in non-treated plants (Fig. 6).

\section{Amino acid production in response to MO1 inoculation and GB treatment under salinity stress}

Amino acid levels were significantly changed in plants treated with and without MO1 and GB under normal and salinity stress conditions (Fig. 7). Under normal conditions, GB treatment and MO1 inoculation significantly up-regulated serine (48.55 and 46.5\%), methionine (38.89 and $22.22 \%$ ), glycine (29.77 and $19.85 \%)$, threonine (17.07 and $21.95 \%$ ), and proline (34.68 and 29.61\%), respectively, compared to levels in non-treated plants (Fig. 7).

Under saline conditions, higher amounts of serine, glycine, methionine, and proline were found in GB-treated plants, with 69.42, 22.76, 124.99, and 48.38\% increases, respectively, followed by MO1-inoculated plants, with $43.78,14.48,100$, and $36.92 \%$ increases, respectively, compared to levels in non-treated plants (Fig. 7). Significantly enhanced amount of threonine $(70 \%)$ was recorded in MO1-inoculated plants followed by GB treatment (63.08\%) compared to control (Fig. 7).

\section{Endogenous $\mathrm{ABA}$ modulation by $\mathrm{MO} 1$ and GB under stress}

Stress-responsive endogenous ABA was notably modulated in MO1-inoculated and GB-treated plants (Fig. 8).
The results indicated that under control conditions, GB treatment significantly decreased the endogenous ABA level by $45 \%$ and that MO1 inoculation decreased it by $30.28 \%$ compared to the level in non-treated plants (Fig. 8).

The salinity stress exposure increased the endogenous ABA level in plants, while the MO1 inoculation and GB treatment significantly reduced the endogenous ABA level by 30.04 and $35.35 \%$, respectively, compared to non-treated plants (Fig. 8).

\section{Discussion}

The utilization of plant growth-promoting microbes for stress tolerance is an ideal and eco-friendly strategy [29]. To date, several studies have been carried out, in which PGPR were utilized for their potent role in salinity stress mitigation [27, 34-37]. Thus, the current study was intended to isolate an halotolerant IAA-producing bacteria and assess its potential to promote tomato (Solanum lycopersicum L.) growth and tolerance against salinity stress, and the selected isolate was identified as L. adecarboxylata MO1 (Figs. 1 and 2). L. adecarboxylata, formerly known as Escherichia adecarboxylata, belongs to the Enterobacteriaceae family [38]. Because of electrophoretic and nucleic differences, the E. adecarboxylata was separated from the Enterobacter agglomerans and reclassified as $L$. adecarboxylata [39]. $L$. adecarboxylata is widely distributed in nature and has been isolated from various sources, including seeds, 


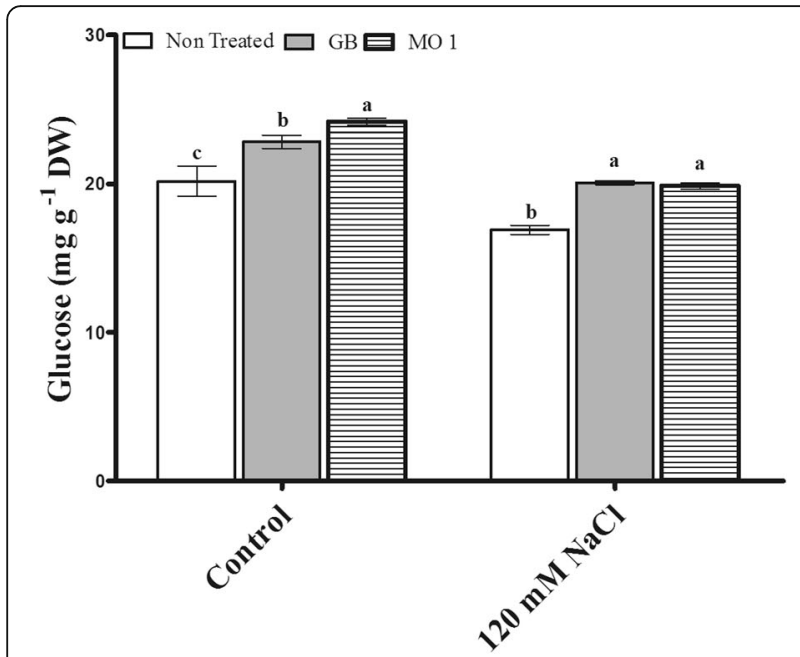

Fig. 5 Sugar (glucose, sucrose, and fructose) regulation in response to $L$. adecarboxylata $\mathrm{MO} 1$ inoculation and GB treatment under normal and saline conditions. Bars with different letters indicate significant differences $(P \leq 0.05)$ among treatments based on DMRT. Each value represents the mean \pm SD of six replicates from each of three independent experiments

plants, rhizosphere, food, water, and various other environmental sources [38-42].

L. adecarboxylata is metabolically diverse and can produce phytohormones, synthesize extra-cellular enzymes, degrade hydrocarbons, and solubilize minerals [40, 4345]. Such traits have been reported to improve plant growth and mitigate various stresses [46]. Enzymes include ACC (1-aminocyclopropane-1-carboxylic acid) daeminase are related with free living rhizobacteria, which play an important role in facilitating plant growth [47]. In current study L. adecarboxylata MO1 showed

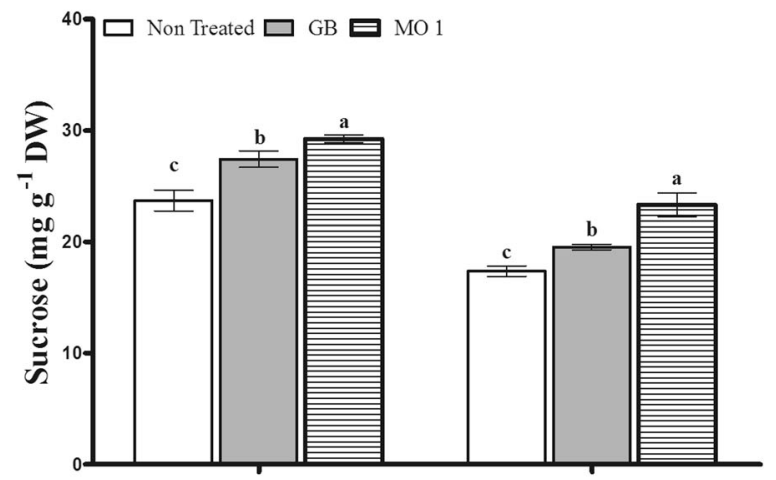
the presence of genes responsible for the deamination of ACC (Fig. 1). ACC, the immediate precursor for ethylene synthesis in plants is exuded from roots of plants, which is metabolized by bacteria having the potential to produce ACC deaminase [48]. ACC deaminase catalyzes the conversion of ACC to ammonia and $\alpha$-ketobutyrate [49]. This conversion lower the ethylene level in plants and resulted in plant growth promotion. Moreover, there is much less ethylene in the presence of ACC deaminase and consequent ethylene feedback inhibition of IAA signal transduction, so that bacteria IAA can continue to promote the growth and increase ACC synthase transcription. This IAA and ACC deaminase cross-talking resulted in lowering the ethylene level and revealed that ACC deaminase facilitate the plant growth by IAA [47]. The IAA-producing potential of $L$. adecarboxylata MO1 (Fig. 1) is in line with that reported by Shahzad et al.

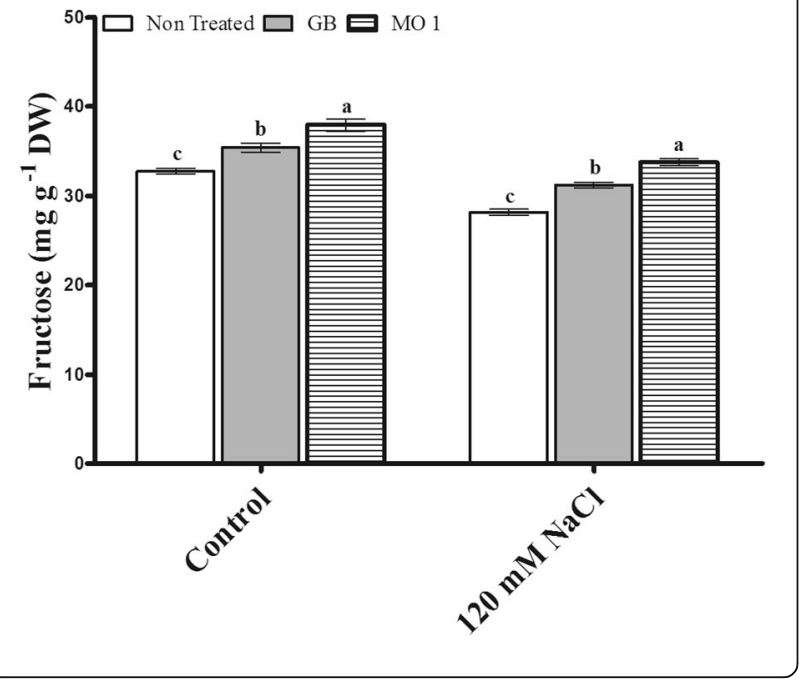
[40]. Moreover, the growth-promoting of capability of $L$. adecarboxylata has been widely reported [50]; however, the role of $L$. adecarboxylata in stress mitigation is not well understood, making the proper investigation of its potent role in mitigating stress and improving stress tolerance necessary. The current study is the first report on the salinity stress mitigation potential of $L$. adecarboxylata.

In our study, salinity stress caused a drastic decrease in the chlorophyll fluorescence (Fv/Fm) of plants. However, the MO1 inoculation and GB treatment increased the chlorophyll fluorescence (Fig. 4). The increase in chlorophyll fluorescence under normal and stress conditions following $L$. adecarboxylata inoculation and GB treatment might be linked to the enhanced pigment synthesis [51]. Moreover, during chlorophyll synthesis, plants fix the carbon dioxide into sugar by using sunlight [52]. Sugar (glucose, sucrose, and fructose) is an important source of energy to stimulate plant growth and 

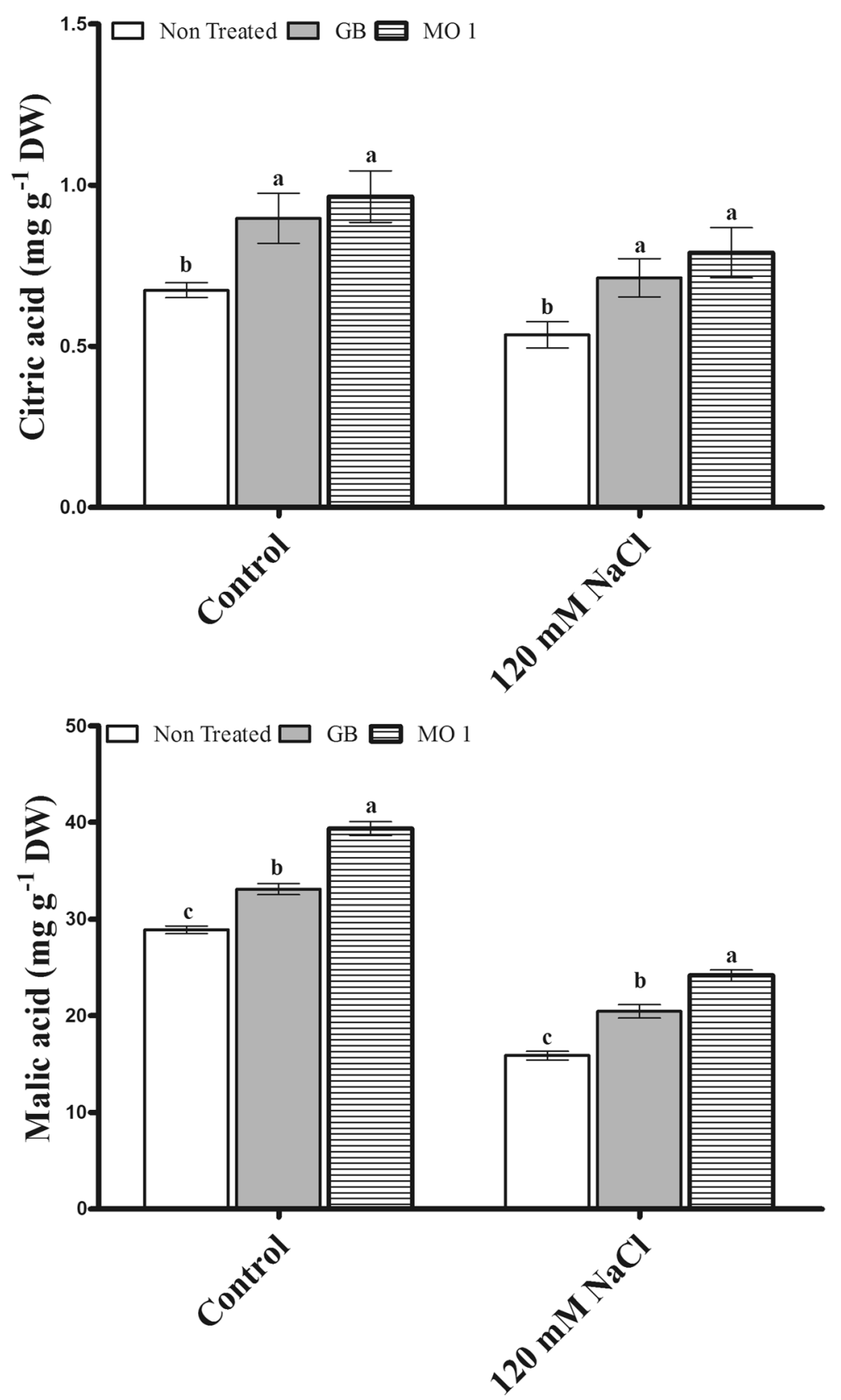

Fig. 6 Organic acid regulation resulting from L. adecarboxylata MO1 inoculation and GB treatment under normal and saline conditions. Bars with different letters indicate significant differences $(P \leq 0.05)$ among treatments based on DMRT. Each value represents the mean \pm SD of six replicates from each of three independent experiments

survival under normal and stress conditions [53, 54]. High compatible sugar contents play an important role in salinity stress mitigation and enhanced plant tolerance. In the current study, L. adecarboxylata MO1 inoculation and GB treatment significantly increased the sugar (glucose, sucrose, and fructose) contents in plants grown under normal and salinity stress conditions, while a reduced level of soluble sugar in plants under stress condition, suggesting the positive role of $L$. adecarboxylata MO1 and GB in salinity stress (Fig. 5). Under saline conditions, the thylakoid membranes are damaged, which results in reduced photosynthetic efficiency and less soluble sugar production [51].

Phytobeneficial microorganisms can stimulate organic acid metabolism in plants under stress conditions [55, 56]. Organic acids play an important role as a solute in osmatic adjustment and excess cation balance under salinity stress [55]. In the current study, the MO1 

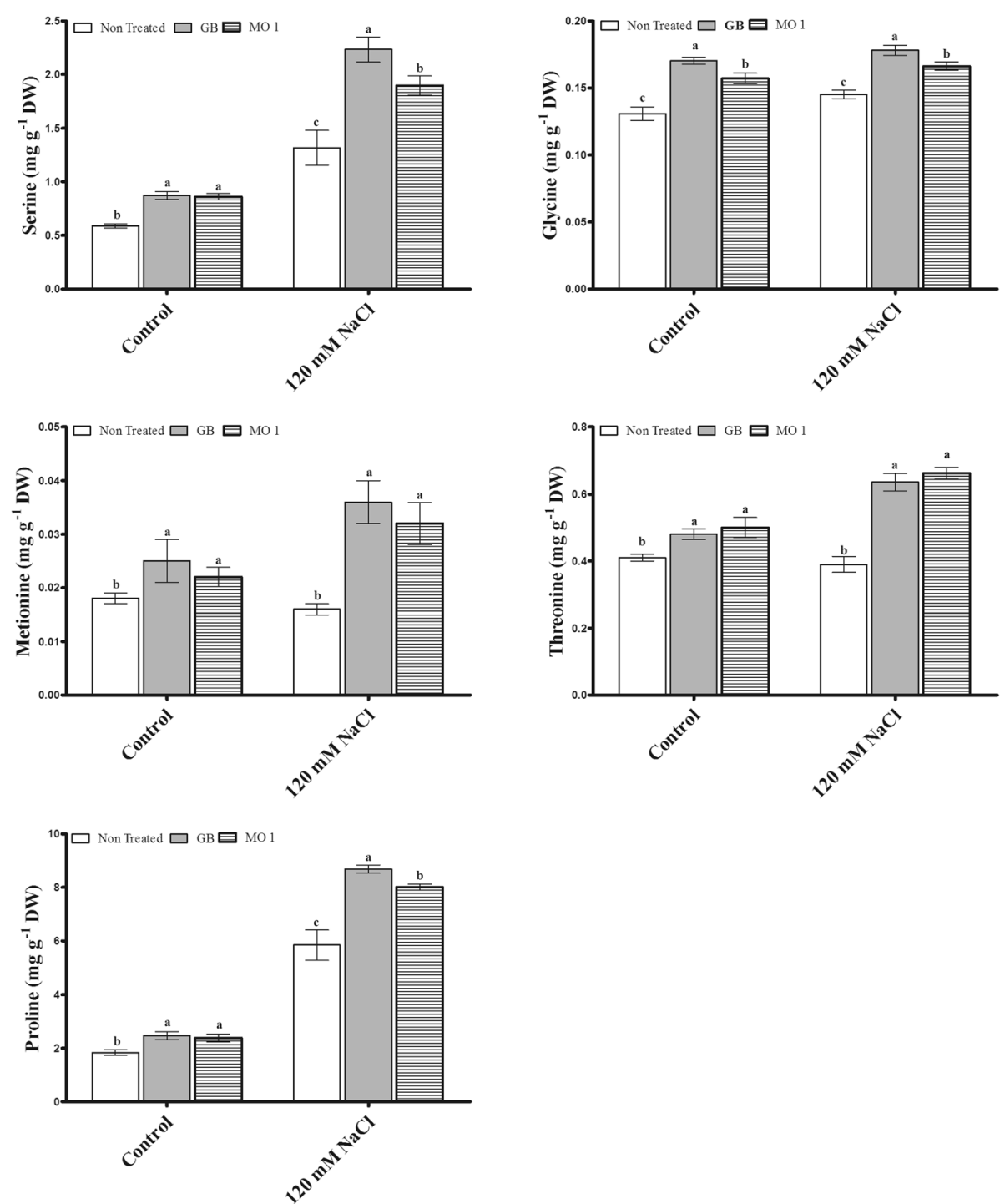

Fig. 7 Amino acid regulation by L. adecarboxylata MO1 and GB treatment in plants under normal and saline conditions. Bars with different letters indicate significant differences $(P \leq 0.05)$ among treatments based on DMRT. Each value represents the mean \pm SD of six replicates from each of three independent experiments

inoculation and GB treatment significantly increased organic acids under normal as well as under salinity stress conditions (Fig. 6). Similar results of increases in organic acids following inoculation with plant growth-promoting bacteria under osmotic stress have been reported [55, 57]. Organic acids also help plants cope with nutrient deficiencies and stress tolerance because they have the potent ability to displace phosphorus from insoluble complexes and make it available for uptake by plants [58]. Moreover, organic acids have also been reported to be involved in plant microbe interactions at the root/soil interface, as organic acids secreted by roots are known to act in chemical signaling for quorum sensing, exopolysaccharide secretion, and biofilm formation during rhizosphere colonization $[59,60]$.
Amino acids are also used as either precursors or intermediates for important metabolites responsible for mitigating various biotic and abiotic stresses [61, 62]. In addition, plant growth-promoting microbes also secrete amino acids in soil, and plants absorb them through their roots via important mechanisms [63, 65]. The increased levels of amino acids in MO1-inoculated and GB-treated plants under normal and salinity stress conditions (Fig. 7) reflected their role in strengthening plant tolerance against salinity stress by various mechanisms [24].

In the current study, the endogenous ABA level was significantly reduced by MO1 inoculation and GB treatment (Fig. 8). The decrease in the ABA level revealed positive correlation between $\mathrm{MO} 1$ and $\mathrm{GB}$ and plant 


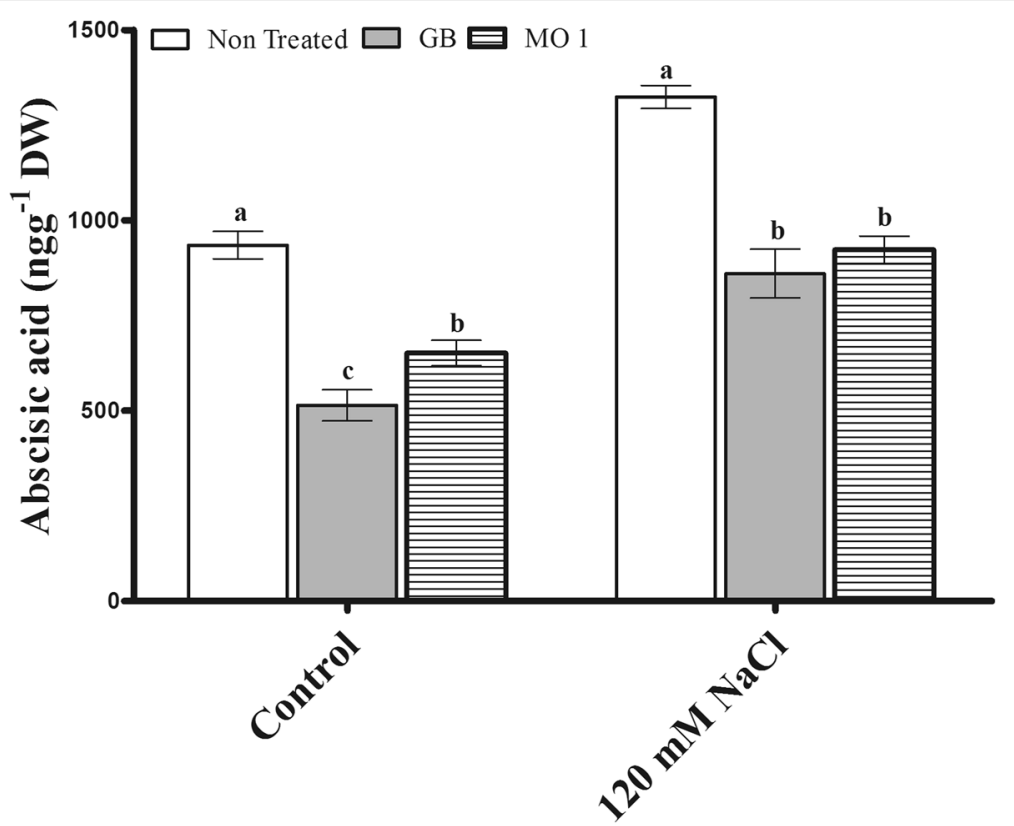

Fig. 8 Influence of L. adecarboxylata MO1 inoculation and GB treatment on endogenous ABA levels in plants under normal and saline conditions. Bars with different letters indicate significant differences $(P \leq 0.05)$ among treatments based on DMRT. Each value represents the mean \pm SD of six replicates from each of three independent experiments

growth and stress tolerance. As ABA is involved in stress signaling, its biosynthesis can be affected during plant growth-promoting microbe interactions [24, 64]. Several studies have reported increases in ABA under salinity and osmotic stresses. However, many plant growth-promoting microbes have been reported to reduce ABA accumulation under stress conditions [24, 37, 65]. However, some microorganisms have also been reported to increase the endogenous ABA level, but the effect depends on the various classes of microorganisms [66]. The reduction of ABA accumulation in MO1-inoculated plants is correlated with its IAA-producing capability, resulting in improved plant growth and improved water relation [67], suggesting an active role of PGPRB in stress resistance.

\section{Conclusion}

Salinity stress is one the major factors that hinder agriculture productivity, and the development of stress-resistant varieties via breeding and genetic engineering is a lengthy and expensive process. However, the utilization of plant growth-promoting microbes to alleviate stress is a more cost-effective and environmentally friendly approach. Delivery of ACC-deaminase and IAA via PGPR mostly affected ethylene and ABA-dependent signaling in positive way which facilitate plant growth and mitigate stressful condition positively [47]. The results of our study indicated that halotolerant $L$. adecarboxylata MO1 could reprogram plants under salinity stress to improve their growth and provide resistance via ACC deaminase synthesis and IAA production which significantly modulate plants endogenous sugar, organic acids, amino acids and stress responsive ABA. These results will guide the necessary future studies for tomato cultivation in areas where salinity is a major constraint. However, further research is required to validate the effectiveness of this PGPR isolate before recommendation for large scale at the field level.

\section{Methods}

Isolation

Soil samples having T-N $0.171 \%, \mathrm{P}_{2} \mathrm{O}_{5}$ 0.026\%, K 0.029 ppm, Na $0.050 \mathrm{ppm}, \mathrm{Ca} 0.057 \mathrm{ppm}$ and $\mathrm{Mg} 0.094 \mathrm{ppm}$ were collected from Gyeongbuk province in South Korea for isolation of bacteria from rhizosphere of tomato according to the method described by Kang et al. [65]. Briefly, collected soil samples (10 g) were transferred to a $250 \mathrm{~mL}$ flask containing $100 \mathrm{~mL}$ Amies solution [69] and then serially diluted to $1 \times 10^{-4}$. Then, a $0.1 \mathrm{~mL}$ suspension was spread on tryptic soy agar plates (TSA; Merck Co., Germany) and incubated at $28^{\circ} \mathrm{C}$ for $24 \mathrm{~h}$. The incubated plates were examined every $6 \mathrm{~h}$ to assess bacterial growth, and the newly appeared bacteria were re-streaked on new plates to get obtain colonies. Single pure colonies were cultured in LB (Luria-Bertani) broth.

\section{Selection of effective isolate}

The initial screening for halotolerant IAA and ACC deaminase producing bacteria was carried out according to the method described by Shahzad et al. [24]. Briefly, 1 $\mathrm{mL}$ Salkowski reagent was added to $1 \mathrm{~mL}$ culture filtrate 
of bacterial isolates. Among the various bacterial isolates, MO1 changed the color to pink, indicating that MO1 produced IAA [68].

Moreover, presence of ACC deaminase responsible gene 'acdS were examined by PCR analysis using $\left(5^{\prime}-3^{\prime}\right)$ primers (Forward: ATCGGCGGCATCCAGWSNAAYCANAC and Reverse: GTGCATCGACTTGCCCTCRTANACNGGRT) as describe by Wang et al. [70]. Briefly, PCR was carried out for 35 cycles with the initial denaturation at $94{ }^{\circ} \mathrm{C}$ for $3 \mathrm{~min}$, cyclic denaturation at $94^{\circ} \mathrm{C}$ for $30 \mathrm{~s}$, annealing $58^{\circ} \mathrm{C}$ for $30 \mathrm{~s}$ and extension at $72^{\circ} \mathrm{C}$ for 2 min with a final extension of $7 \mathrm{~min}$ at $72^{\circ} \mathrm{C}$ using $50 \mu \mathrm{L}$ reaction mixture containing $50 \mathrm{ng}$ of DNA, 20 pmoles of each primer, 1.25 units of Taq DNA polymerase, $200 \mu \mathrm{M}$ of each dNTPs and 1× PCR buffer. Moreover the PCR product was examined by agarose gel electrophoresis.

In addition, the salinity tolerance potential of MO1 in a saline environment was investigated according to the method described by Shahzad et al. [24]. Briefly, MO1 was grown in three concentrations of $\mathrm{NaCl}(120,250$, and $500 \mathrm{mM}$ ) in LB media ( $10 \mathrm{~g}$ tryptone, $5 \mathrm{~g}$ yeast extract, $10 \mathrm{~g} \mathrm{NaCl}, \mathrm{pH} 7.0 \pm 0.2$, autoclaved for $15 \mathrm{~min}$ at $121^{\circ} \mathrm{C}$ ) to determine its growth dynamics and salinity tolerance capability. Growth dynamics were assessed using bacterial cell density at $\mathrm{OD}_{600}$ (T60 UV VIS Spectrophotometer).

\section{Phylogenetic analysis}

The MO1 bacterial strain was identified by PCR amplification and sequencing of 16S rRNA and phylogenetic analysis. The specific $27 \mathrm{~F}$ primer $\left(5^{\prime}\right.$-AGAGTTTGATC (AC) TGGCTCAG-3') and 1492R primer (5'-CGG (CT) TACCTTGTTACGACTT-3') were used for PCR as described by Shahzad et al. [71].

\section{IAA quantification by $\mathrm{GC} / \mathrm{MS}$}

IAA produced by MO1 in culture broth without L-Trp was extracted and analyzed by GC/MS with selected ion monitoring (SIM; $6890 \mathrm{~N}$ network GC system and 5973 network mass selective detector; Agilent Technologies, Santa Clara, CA, USA). The GC/MS conditions used for IAA quantification are given in the supplementary table (Additional file 1: Table S1) according to the method described by Shahzad et al. [40].

\section{Salinity stress application and PGPR inoculation}

A plant microbe interaction experiment was carried out to confirm the growth-promoting and stress-mitigating potential of the isolated L. adecarboxylata MOI. The experiment was carried out in complete randomized design with six treatments (Control, MO1, and GB each with and without $120 \mathrm{mM} \mathrm{NaCl}$ ) in triplicate. Tomato (Solanum lycopersicum L. 'Yegwang') seeds were purchased from Danong Co. (Korea) and surface sterilized with $70 \% \mathrm{EtoH}$ followed by $2.5 \% \mathrm{NaOH}$ and rinsed with deionized distilled water and were germinated at $28^{\circ} \mathrm{C}$ in an incubator. Equal-sized seedlings (1 seedling per pot) were moved to sterilized plastic pots $(10 \mathrm{~cm}$ width and $9 \mathrm{~cm}$ height) filled with $500 \mathrm{mg}$ autoclaved horticultural substrate composed of peat moss (10-15\%), coco peat (45-50\%), perlite (35-40\%), and zeolite (6-8\%) with the $\mathrm{NO}_{3}^{-}\left(\sim 0.205 \mathrm{mg} \mathrm{g}^{-1}\right), \mathrm{NH}^{4+}\left(\sim 0.09 \mathrm{mg} \mathrm{g}^{-1}\right), \mathrm{P}_{2} \mathrm{O}_{5}$ $\left(\sim 0.35 \mathrm{mg} \mathrm{g}^{-1}\right)$, and $\mathrm{K}_{2} \mathrm{O}\left(\sim 0.1 \mathrm{mgg}^{-1}\right)$. Moreover, the soil pH was $5-7$, bulk density was under $0.3 \mathrm{mg} / \mathrm{m}^{3}$, and EC $(\mathrm{dS} / \mathrm{m})$ was $\leq 1.2$ [19]. The pots were placed in a growth chamber with a fixed program (day/night cycle: $12 \mathrm{~h}$ at $24{ }^{\circ} \mathrm{C}, 12 \mathrm{~h}$ at $20^{\circ} \mathrm{C}$; relative humidity: $65-70 \%$; $1000 \mu \mathrm{E} m-2 \mathrm{~s}-1$ from sodium lamps). After two weeks, the pots were divided into six group according to the experimental design with 30 plants per treatment in triplicate. The plants were inoculated with $20 \mathrm{~mL} \mathrm{MO1}$ $\left(4 \times 10^{8}\right.$ cells $\left.\mathrm{mL}^{-1}\right)$ and treated with GB followed by 50 $\mathrm{mL} 120 \mathrm{mM} \mathrm{NaCl}$ for 10 days on a daily basis to induce salinity-induced osmotic stress [72, 73]. Upon stress completion (10 days) at vegetative growth stage, growth attributes (shoot and root length, shoot and root fresh weight, stem diameter, and chlorophyll content) were recorded and the plants were immediately harvested in liquid nitrogen and stored in $-80^{\circ} \mathrm{C}$ until further biochemical analyses.

\section{Chlorophyll content assessment}

Chlorophyll content was examined using a CCM-300 Chlorophyll Content Meter (Opti-Sciences, Inc., Hudson, $\mathrm{NH}, \mathrm{USA}$ ) as previously described by Kim et al. [74].

\section{Sugar quantification}

The contents of soluble sugars such as glucose, sucrose, and fructose were estimated according to the method described by Khan et al. [75]. Briefly, $0.5 \mathrm{~g}$ freeze dried grinded samples were extracted with $80 \%$ ethanol followed by vacuum drying. The dried residue was re-dissolved in $1 \mathrm{~mL}$ deionized water and passed through $0.45 \mu \mathrm{m}$ Nylon-66 syringe filters. Furthermore, the filtered samples were injected to HPLC (Millipore Co., Waters Chromatography, Milford, MA, USA).

\section{Organic acid estimation}

Organic acids were measured according to the method described by Bilal et al. [76] . Briefly, 0.1 $\mathrm{g}$ of freeze dried grinded samples were added to $9 \mathrm{~mL}$ of distilled water and left overnight at room temperature. Then the sample was passed through a $0.22 \mu \mathrm{m}$ syringe filter and $20 \mu \mathrm{L}$ using HPLC on a model 600E system (Waters, Millford, MA, USA) equipped with a refractive index detector (RI, Model 410) with fixed isocratic conditions (mobile phase: $0.005 \mathrm{M} \mathrm{H}_{2} \mathrm{SO}_{4}$ in water, flow rate 0.6 
$\mathrm{mL} \min ^{-1}$, column temperature $65^{\circ} \mathrm{C}$, PL Hi-Plex $\mathrm{H}$ column).

\section{Amino acid determination}

Amino acids were determined according to the method described by Shahzad et al. [77]. Briefly, freeze dried plant samples were hydrolyzed in $6 \mathrm{~N} \mathrm{HCl}$ under vacuum in $4 \mathrm{~mL}$ tubes at $110^{\circ} \mathrm{C}$ for $24 \mathrm{~h}$, followed by $80^{\circ} \mathrm{C}$ for $24 \mathrm{~h}$. The dried residue was homogenized in $0.02 \mathrm{~N}$ $\mathrm{HCl}$ and was passed through $0.45-\mu \mathrm{m}$ filter. Amino acids were quantified by an automatic amino acid analyzer (HITACHI L-8900, Japan) attached to a HITACHI HPLC system (packed column with ion-exchanging resin, No. 2622 PF; $4.6 \times 60 \mathrm{~mm}$ ) and ultraviolet detector (VIS1: $570 \mathrm{~nm}, \mathrm{VIS} 2: 440 \mathrm{~nm}$ ).

\section{ABA quantification}

ABA was analyzed by GCMS ( $6890 \mathrm{~N}$ network GC system and 5973 network mass selective detector, Agilent Technologies, Palo Alto, CA, USA) according to the method described by Qi et al. [78]. Moreover, $\left[( \pm)-3,5,5,7,7,7-\mathrm{d}^{6}\right]-\mathrm{ABA}$ was added as internal standard and for quantification, the Lab-Base (ThermoQuset, Manchester, UK) data system software was used to monitor responses to ions of $\mathrm{m} / \mathrm{e} 162$ and 190 for Me-ABA Me- $\left[{ }^{2} \mathrm{H}_{6}\right]-\mathrm{ABA}$ and $m / z 166$ and 194 for $\mathrm{Me}-[2 \mathrm{H} 6]-\mathrm{ABA}$.

\section{Statistical analysis}

The data which are presented as means \pm standard deviation were collected and pooled from triplicate treatments from each of three independently repeated experiments and were subjected to Duncan's multiple range test (DMRT) using SAS version 9.2 (Cary, NC, USA). Graphs were constructed using GraphPad prism. Moreover, the biochemical data obtained from each repetition were pooled together for their respective treatment and grouped into normal and stress conditions. A two-way analysis of variance (ANOVA) was performed to determine the significance level $(P<0.05)$. The two way ANOVA table is given in the Additional file 2: Table S2.

\section{Additional files}

Additional file 1: Table S1. GC/MS - SIM conditions used for analysis and quantification of the indole-3-acetic acid. (DOCX $12 \mathrm{~kb}$ )

Additional file 2: Table S2. Two-way ANOVA table of the biochemical analysis performed for tomato plants with and without MO1 inoculation and GB treatment under normal and $120 \mathrm{mM} \mathrm{NaCl}$ stress. (DOCX $18 \mathrm{~kb}$ )

\section{Abbreviations}

ABA: Abscisic acid; GA: Gibberellins.; GB: Glycine betaine; IAA: Indole-3-acetic acid
Acknowledgements

Not applicable.

\section{Funding}

This study was supported by the Basic Science Research Program through the National Research Foundation of Korea (NRF) funded by the Ministry of Education (2016R1D1A3B03931629). The funding body had no role in the design of the study and collection, analysis, and interpretation of data and in writing the manuscript.

\section{Availability of data and materials}

All data generated or analyzed during this study are included in this published article.

\section{Authors' contributions}

SMK and RS conceived the idea, carried out the experiments, collected the data, and wrote the manuscript. SB, YGP, KEL, MAK and SA helped in the biochemical analyses. ALK contributed to the data analysis. IJL, as the team leader, supervised the design and conducting of all experiments and provided the relevant facilities, financial support, and mentorship. All authors have read and approved the final manuscript.

Ethics approval and consent to participate Not applicable.

\section{Consent for publication}

Not applicable.

\section{Competing interests}

All authors have no competing interests.

\section{Publisher's Note}

Springer Nature remains neutral with regard to jurisdictional claims in published maps and institutional affiliations.

\section{Author details}

${ }^{1}$ Institute of Agricultural Science and Technology, Kyungpook National University, Daegu 41566, Republic of Korea. ${ }^{2}$ Basic and Applied Scientific Research Center, Imam Abdulrahman Bin Faisal University, Dammam, Saudi Arabia. ${ }^{3}$ School of Applied Biosciences, Kyungpook National University, Daegu 41566, Republic of Korea. ${ }^{4}$ Natural and Medical Sciences Research Center, University of Nizwa, Nizwa, Oman.

Received: 16 August 2018 Accepted: 2 April 2019

Published online: 25 April 2019

\section{References}

1. Pereira A. Plant abiotic stress challenges from the changing environment. Front Plant Sci. 2016;7:1123.

2. Shabala S, Munns R. Salinity stress: physiological constraints and adaptive mechanisms. In: Plant Stress Physiol. 2nd ed. Wallingford: CABl; 2017. p. 2463.

3. Cheeseman J. Food security in the face of salinity, drought, climate change, and population growth: Halophytes for Food Security in Dry Lands. Elsevier; 2016. p. $111-23$

4. Dagar JC. Agroforestry for the Management of Waterlogged Saline Soils and Poor- quality Waters Advances in Agroforestry; 2016; February. https://doi. org/10.1007/978-81-322-2659-8 2.

5. Zhu J-K. Plant salt tolerance. Trends Plant Sci. 2001;6:66-71.

6. Hussain MI, Al-Dakheel AJ, Reigosa MJ. Genotypic differences in agrophysiological, biochemical and isotopic responses to salinity stress in quinoa (Chenopodium quinoa Willd.) plants: prospects for salinity tolerance and yield stability. Plant Physiol Biochem. 2018;129:411-20.

7. Petropoulos SA, Levizou E, Ntatsi G, Fernandes Â, Petrotos K, Akoumianakis $K$, et al. Salinity effect on nutritional value, chemical composition and bioactive compounds content of Cichorium spinosum L. Food Chem. 2017; 214:129-36.

8. Asrar H, Hussain T, Hadi SMS, Gul B, Nielsen BL, Khan MA. Salinity induced changes in light harvesting and carbon assimilating complexes of Desmostachya bipinnata (L.) Staph. Environ Exp Bot. 2017;135:86-95. 
9. Ishikawa T, Shabala S. Control of xylem Na+ loading and transport to the shoot in rice and barley as a determinant of differential salinity stress tolerance. Physiol Plant. 2018.

10. Garg N, Bhandari P. Silicon nutrition and mycorrhizal inoculations improve growth, nutrient status, $\mathrm{K}+/ \mathrm{Na}+$ ratio and yield of Cicer arietinum $\mathrm{L}$. genotypes under salinity stress. Plant Growth Regul. 2016;78:371-87.

11. Flowers TJ, Flowers SA. Why does salinity pose such a difficult problem for plant breeders? Agric Water Manag. 2005;78:15-24.

12. Fan $Y$, Bose J, Zhou M, Shabala S. ROS production, scavenging, and signaling under salinity stress. Manag Salt Toler Plants Mol Genomic Perspect. 2015;187.

13. Pang C-H, Wang B-S. Oxidative stress and salt tolerance in plants: Progress in botany. Springer; 2008. p. 231-45.

14. Yurtseven E, Kesmez GD, Ünlükara A. The effects of water salinity and potassium levels on yield, fruit quality and water consumption of a native central anatolian tomato species (Lycopersicon esculantum). Agric Water Manag. 2005;78:128-35.

15. Singh J, Sastry ED, Singh V. Effect of salinity on tomato (Lycopersicon esculentum mill.) during seed germination stage. Physiol Mol Biol Plants. 2012;8(1):45-50.

16. La Pena RD, Hughes J. Improving vegetable productivity in a variable and changing climate. Journal of Semi-Arid Tropical Agricultural Research. 2007; $4: 22$.

17. Wu M, Kubota C. Effects of electrical conductivity of hydroponic nutrient solution on leaf gas exchange of five greenhouse tomato cultivars. HortTechnology. 2008;18(2):271-7.

18. Sato S, Sakaguchi S, Furukawa $\mathrm{H}$, Ikeda $\mathrm{H}$. Effects of $\mathrm{NaCl}$ application to hydroponic nutrient solution on fruit characteristics of tomato (Lycopersicon esculentum mill.). Sci Hortic. 2006;109(3):248-53.

19. Shahzad R, Khan AL, Bilal S, Asaf S, Lee I-J. What is there in seeds? Vertically transmitted endophytic resources for sustainable improvement in plant growth. Front Plant Sci. 2018;9.

20. Shameer S, Prasad T. Plant growth promoting rhizobacteria for sustainable agricultural practices with special reference to biotic and abiotic stresses. Plant Growth Regul. 2018;84:603-15.

21. Yang J, Kloepper JW, Ryu C-M. Rhizosphere bacteria help plants tolerate abiotic stress. Trends Plant Sci. 2009;14:1-4.

22. Mishra J, Fatima T, Arora NK. Role of Secondary Metabolites from Plant Growth-Promoting Rhizobacteria in Combating Salinity Stress. In: Plant Microbiome: Stress Response. Springer; 2018. p. 127-163.

23. Fukami J, de la Osa C, Ollero FJ, Megías M, Hungria M. Co-inoculation of maize with Azospirillum brasilense and rhizobium tropici as a strategy to mitigate salinity stress. Funct Plant Biol. 2018;45:328-39.

24. Shahzad R, Khan AL, Bilal S, Waqas M, Kang S-M, Lee I-J. Inoculation of abscisic acid-producing endophytic bacteria enhances salinity stress tolerance in Oryza sativa. Environ Exp Bot. 2017;136.

25. Kumar A, Singh VK, Tripathi V, Singh PP, Singh AK. Plant growth-promoting Rhizobacteria (PGPR): perspective in agriculture under biotic and abiotic stress: Crop Improvement Through Microbial Biotechnology. Elsevier; 2018 p. 333-42.

26. Patel TS, Minocheherhomji FP. Plant growth promoting Rhizobacteria: blessing to agriculture. Int J Pure App Biosci. 2018;6:481-92.

27. Vimal SR, Patel VK, Singh JS. Plant growth promoting Curtobacterium albidum strain SRV4: an agriculturally important microbe to alleviate salinity stress in paddy plants. Ecol Indic. 2018.

28. Sapre S, Gontia-Mishra I, Tiwari S. Klebsiella sp. confers enhanced tolerance to salinity and plant growth promotion in oat seedlings (Avena sativa). Microbiol Res. 2018;206:25-32.

29. Kumar K, Amaresan N, Madhuri K. Alleviation of the adverse effect of salinity stress by inoculation of plant growth promoting rhizobacteria isolated from hot humid tropical climate. Ecol Eng. 2017;102:361-6.

30. Fazal A, Bano A. Role of plant growth-promoting rhizobacteria (pgpr), biochar, and chemical fertilizer under salinity stress. Commun Soil Sci Plant Anal. 2016:47:1985-93.

31. Latif Khan A, Ahmed Halo B, Elyassi A, Ali S, Al-Hosni K, Hussain J, et al. Indole acetic acid and ACC deaminase from endophytic bacteria improves the growth of solarium lycopersicum. Electron J Biotechnol. 2016;19:58-64.

32. Dakora FD, Phillips DA. Root exudates as mediators of mineral acquisition in low-nutrient environments. In: Food Security in Nutrient-Stressed Environments. Springer: Exploiting Plants' Genetic Capabilities; 2002. p. 201-13.
33. Gamalero E, Glick BR. Bacterial modulation of plant ethylene levels. Plant Physiol. 2015 Sep 1;169(1):13-22.

34. Yousefi S, Kartoolinejad D, Bahmani M, Naghdi R. Effect of Azospirillum lipoferum and Azotobacter chroococcum on germination and early growth of hopbush shrub (Dodonaea viscosa L.) under salinity stress. J Sustain For. 2017;36:107-20.

35. Habib SH, Kausar H, Saud HM. Plant growth-promoting rhizobacteria enhance salinity stress tolerance in okra through ROS-scavenging enzymes. Biomed Res Int. 2016;2016.

36. Paulucci NS, Gallarato LA, Reguera YB, Vicario JC, Cesari AB, de Lema MBG, et al. Arachis hypogaea PGPR isolated from argentine soil modifies its lipids components in response to temperature and salinity. Microbiol Res. 2015;173:1-9.

37. Kang S-M, Khan AL, Waqas M, You Y-H, Kim J-H, Kim J-G, et al. Plant growth-promoting rhizobacteria reduce adverse effects of salinity and osmotic stress by regulating phytohormones and antioxidants in Cucumis sativus. J Plant Interact. 2014;9:673-82.

38. Richard C. Nouvelles espèces de Enterobacteriaceae. Bull Inst Pasteur. 1984; 82:255-77.

39. Tamura K, Sakazaki R, Kosako Y, Yoshizaki E. Leclercia adecarboxylata gen. Nov., comb. Nov., formerly known asEscherichia adecarboxylata. Curr Microbiol. 1986;13:179-84.

40. Shahzad R, Waqas M, Khan AL, Al-Hosni K, Kang S-M, Seo C-W, et al. Indoleacetic acid production and plant growth promoting potential of bacterial endophytes isolated from rice (Oryza sativa L.) seeds. Acta Biol Hung. 2017;68.

41. Verma P, Yadav AN, Khannam KS, Panjiar N, Kumar S, Saxena AK, et al. Assessment of genetic diversity and plant growth promoting attributes of psychrotolerant bacteria allied with wheat (Triticum aestivum) from the northern hills zone of India. Ann Microbiol. 2015;65:1885-99.

42. Kelemu S, Fory P, Zuleta C, Ricaurte J, Rao I, Lascano C. Detecting bacteria endophytes in tropical grasses of the Brachiaria genus and determining their role in improving plant growth. African J Biotechnol. 2011;10:965-76

43. Sun K, Liu J, Gao Y, Jin L, Gu Y, Wang W. Isolation, plant colonization potential, and phenanthrene degradation performance of the endophytic bacterium Pseudomonas sp. Ph6-gfp. Sci Rep. 2014;4:5462.

44. Pei-Xiang Y, Li MA, Ming-Hui C, Jia-Qin XI, Feng HE, Chang-Qun D, et al. Phosphate solubilizing ability and phylogenetic diversity of bacteria from P-rich soils around Dianchi Lake drainage area of China. Pedosphere. 2012;22:707-16.

45. Sarma PM, Bhattacharya D, Krishnan S, Lal B. Degradation of polycyclic aromatic hydrocarbons by a newly discovered enteric bacterium. Leclercia adecarboxylata Appl Environ Microbiol. 2004;70:3163-6.

46. Paul S, Dukare AS, Manjunatha BS, Annapurna K. lant Growth-Promoting Rhizobacteria for Abiotic Stress Alleviation in Crop. In: Advances in Soil Microbiology. Springer: Recent Trends and Future Prospects; 2017. p. 57-79.

47. Glick BR. Bacteria with ACC deaminase can promote plant growth and help to feed the world. Microbiol Res. 2014;169:30-9.

48. Penrose DM, Moffatt BA, Glick BR. Determination of 1-aminocycopropane-1carboxylic acid (ACC) to assess the effects of ACC deaminase-containing bacteria on roots of canola seedlings. Can J Microbiol. 2001;47:77-80.

49. Penrose DM, Glick BR. Methods for isolating and characterizing ACC deaminase-containing plant growth-promoting rhizobacteria. Physiol Plant. 2003;118:10-5.

50. Kisiel A, Kępczyńska E. Medicago truncatula Gaertn. As a model for understanding the mechanism of growth promotion by bacteria from rhizosphere and nodules of alfalfa. Planta. 2016:243:1169-89.

51. Radhakrishnan R, Lee IJ. Effect of low dose of spermidine on physiological changes in salt-stressed cucumber plants. Russ J Plant Physiol. 2014;61:90-6. https://doi.org/10.1134/S1021443714010129.

52. Gupta AK, Kaur N. Sugar signalling and gene expression in relation to carbohydrate metabolism under abiotic stresses in plants. J Biosci. 2005;30:761-76.

53. Sami F, Yusuf M, Faizan M, Faraz A, Hayat S. Role of sugars under abiotic stress. Plant Physiol Biochem. 2016;109:54-61.

54. Lastdrager J, Hanson J, Smeekens S. Sugar signals and the control of plant growth and development. J Exp Bot. 2014;65:799-807. https://doi.org/10. 1093/jxb/ert474.

55. Esringü A, Kaynar D, Turan M, Ercisli S. Communications in Soil Science and Plant Analysis Ameliorative Effect of humic acid and plant growthpromoting Rhizobacteria ( PGPR ) on Hungarian vetch plants under salinity stress ameliorative effect of humic acid and plant growth-promoting. Commun Soil Sci Plant Anal. 2016:47:602-18. https://doi.org/10.1080/ 00103624.2016 .1141922 
56. Lugtenberg BJ, Malfanova N, Kamilova F, Berg G. Plant Growth Promotion by Microbes. Molecular microbial ecology of the rhizosphere. 2013. 3;2:561-573.

57. Cramer GR, Ergül A, Grimplet J, Tillett RL, Tattersall EAR, Bohlman MC, et al. Water and salinity stress in grapevines: early and late changes in transcript and metabolite profiles. Funct Integr Genomics. 2007;7:111-34. https://doi. org/10.1007/s10142-006-0039-y.

58. Richardson AE, Barea J, McNeill AM, Prigent-Combaret C. Acquisition of phosphorus and nitrogen in the rhizosphere and plant growth promotion by microorganisms. Plant Soil. 2009;321. https://doi.org/10.1007/s11104-0099895-2.

59. Badri DV, Weir TL, Van Der LD, Vivanco JM. Rhizosphere chemical dialogues : plant - microbe interactions; 2009. p. 642-50.

60. Narula N, Kothe E, Behl RK. Role of root exudates in plant-microbe interactions. J Appl Bot Food Qual. 2009:82:122-30.

61. Galili G, Amir R, Fernie AR. The regulation of essential amino acid synthesis and accumulation in plants. Annu Rev Plant Biol. 2016;67:153-78.

62. Radhakrishnan R, Kang S-M, Baek I-Y, Lee I-J. Characterization of plant growth-promoting traits of Penicillium species against the effects of high soil salinity and root disease. J Plant Interact. 2014;9:754-62.

63. Jones DL, Healey JR, Willett VB, Farrar JF, Hodge A. Dissolved organic nitrogen uptake by plants-an important N uptake pathway? Soil Biol Biochem. 2005;37:413-23.

64. Khan AL, Waqas M, Asaf S, Kamran M, Shahzad R, Bilal S, et al. Plant growthpromoting endophyte Sphingomonas sp. LK11 alleviates salinity stress in Solanum pimpinellifolium. Environ Exp Bot. 2017;133:58-69.

65. Kang S-M, Khan AL, Waqas M, You Y-H, Hamayun M, Joo G-J, et al. Gibberellin-producing Serratia nematodiphila PEJ1011 ameliorates low temperature stress in Capsicum annuum L. Eur J Soil Biol. 2015;68.

66. Park Y-G, Mun B-G, Kang S-M, Hussain A, Shahzad R, Seo C-W, et al. Bacillus aryabhattai SRBO2 tolerates oxidative and nitrosative stress and promotes the growth of soybean by modulating the production of phytohormones. PLoS One. 2017:12.

67. Egamberdieva D. Alleviation of salt stress by plant growth regulators and IAA producing bacteria in wheat. Acta Physiol Plant. 2009;31:861-4.

68. Kang S-M, Waqas M, Shahzad R, You Y-H, Asaf S, Khan MA, et al. Isolation and characterization of a novel silicate-solubilizing bacterial strain Burkholderia eburnea CS4-2 that promotes growth of japonica rice (Oryza sativa L. Cv. Dongjin). Soil Sci Plant Nutr. 2017:63.

69. Amies CR. A modified formula for the preparation of Stuart's transport medium. Can J Public Heal Can Sante'e Publique. 1967;58:296-300.

70. Wang Z, Solanki MK, Pang F, Singh RK, Yang L-T, Li Y-R, et al. Identification and efficiency of a nitrogen-fixing endophytic Actinobacterial strain from sugarcane. Sugar Tech. 2017;19:492-500.

71. Shahzad R, Waqas M, Khan AL, Asaf S, Khan MA, Kang S-M, et al. Seed-borne endophytic Bacillus amyloliquefaciens RWL-1 produces gibberellins and regulates endogenous phytohormones of Oryza sativa. Plant Physiol Biochem. 2016:106.

72. Chen S, Gollop N, Heuer B. Proteomic analysis of salt-stressed tomato (Solanum lycopersicum) seedlings: effect of genotype and exogenous application of glycinebetaine. J Exp Bot. 2009;60(7):2005-19.

73. Manai J, Gouia H, Corpas FJ. Redox and nitric oxide homeostasis are affected in tomato (Solanum lycopersicum) roots under salinity-induced oxidative stress. - J. Plant Physiol. 2014;171:1028-35.

74. Kim A-Y, Shahzad R, Kang S-M, Seo C-W, Park Y-G, Park H-J, et al. IAAproducing Klebsiella variicola AY13 reprograms soybean growth during flooding stress. J Crop Sci Biotechnol. 2017;20.

75. Khan AL, Al-Harrasi A, Shahzad R, Imran QM, Yun B-W, Kim Y-H, et al. Regulation of endogenous phytohormones and essential metabolites in frankincense-producing Boswellia sacra under wounding stress. Acta Physiol Plant. 2018;40:113.

76. Bilal S, Khan AL, Waqas M, Shahzad R, Kim I-D, Lee I-J, et al. Biochemical constituents and in vitro antioxidant and anticholinesterase potential of seeds from native Korean persimmon genotypes. Molecules. 2016;21(7):893.

77. Shahzad R, Khan AL, Bilal S, Asaf S, Lee I-J. Plant growth-promoting endophytic bacteria versus pathogenic infections: An example of Bacillus amyloliquefaciens RWL-1 and Fusarium oxysporum f. sp. lycopersici in tomato. PeerJ. 2017;2017.

78. Qi QG, Rose PA, Abrams GD, Taylor DC, Abrams SR, Cutler AJ. Abscisic acid metabolism, 3-ketoacyl-coenzyme a synthase gene expression and verylong-chain monounsaturated fatty acid biosynthesis in Brassica napus embryos. Plant Physio. 1998;117. https://doi.org/10.1104/pp.117.3.979.

Ready to submit your research? Choose BMC and benefit from:

- fast, convenient online submission

- thorough peer review by experienced researchers in your field

- rapid publication on acceptance

- support for research data, including large and complex data types

- gold Open Access which fosters wider collaboration and increased citations

- maximum visibility for your research: over $100 \mathrm{M}$ website views per year

At $\mathrm{BMC}$, research is always in progress.

Learn more biomedcentral.com/submissions 